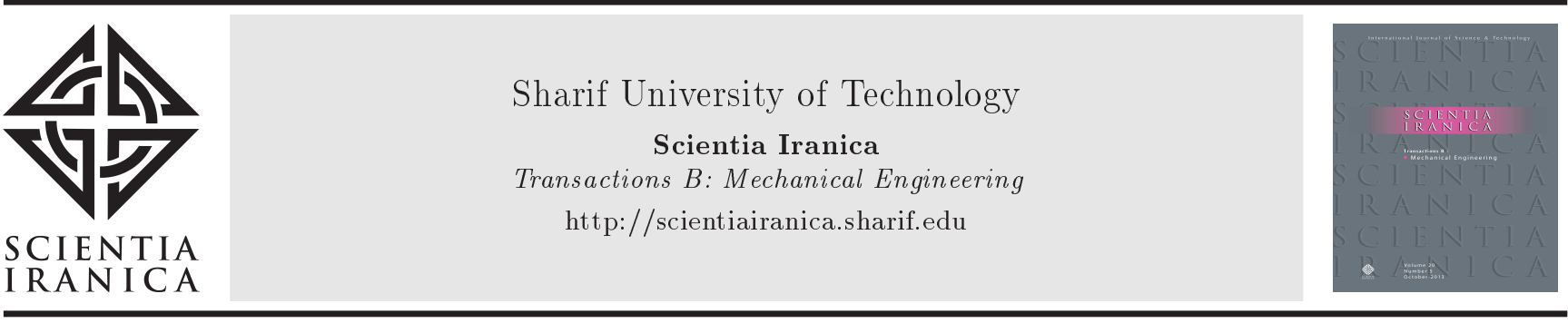

\title{
A CFD study of a flanged shrouded wind turbine: Effects of different flange surface types on output power
}

\author{
N. Maftouni* and M. Taghaddosi \\ Department of Mechanical Engineering, Faculty of Engineering, Alzahra University, Tehran, Iran.
}

Received 11 January 2021; received in revised form 6 March 2021; accepted 3 May 2021

\section{KEYWORDS}

Wind energy;

Shrouded wind turbine;

Flanged shroud;

Furrowed surface

flange.

\begin{abstract}
There is a global trend to optimize energy harvesting from all energy resources including renewable energy. This study focuses on the enhancement of the surface of flanges in flanged shrouded wind turbines so as to obtain more efficient systems. To this end, a Computational Fluid Dynamics (CFD) approach is utilized. All models are identical in terms of entrance diameter, exit diameter, length of the diffuser, and the height of the flange. However, each model is of different flange surface types. Different surfaces including a simple surface and some furrowed surfaces are studied. The validation reports show that there is a strong correlation between the outcomes of the present study and previous experimental results. The results demonstrate that the models with furrowed surface flange yield increase in the wind velocity when approaching the wind turbine blades. This leads to about $5-7 \%$ more output power. Also, the results indicate that maximum velocity occurs at about $5 \mathrm{~cm}$ after the shroud entrance. Consequently, it is suggested that the wind turbine be installed at the mentioned location inside the shroud to obtain the optimum energy harvest.
\end{abstract}

(C) 2022 Sharif University of Technology. All rights reserved.

\section{Introduction}

Combustion of fossil fuels to support energy demand may cause several environmental problems such as climate change, smog, and acid rain. Recently, global efforts have targeted the aim of reducing global reliance on fossil fuels. Hence, this concern has drawn attention to renewable energy resources.

Wind energy is a potential source of renewable energy. Nowadays, wind generator turbines possessing different sizes are being increasingly manufactured. A difference between small- and large-scale wind turbines is that the small-scale wind turbines are usually used for supplying the required power, often within a pre-

\footnotetext{
*. Corresponding author. Tel.: +982188044040;

Fax: +982188617537

E-mail address: n.maftouni@alzahra.ac.ir (N. Maftouni)
}

doi: $10.24200 /$ sci. 2021.57513 .5278 determined setting, not where the wind is most satisfactory. Turbines need to enhance energy capturing to obtain rational power outputs on small scales, mainly at a low wind speed. They should be reactive to the alterations in the wind direction.

\section{Literature review}

The power generated by a wind turbine is proportional to the cubic power of the wind speed. Hence, the energy output greatly increases following a small increase in wind speed. Thus, researchers attempt to increase the speed of wind in the vicinity of wind turbine blades via various methods. The ducted or shrouded wind turbine is a common technique to improve the captured power.

Many research studies have been done in this domain; however, notable aspects remain to be considered experimentally and numerically [1-5]. A theoretical research work was performed by Railbird and Lilley to obtain power output from a completely ducted land- 
type wind turbine $(65 \%$ of the highest power outputs of the ideal bare wind turbine) [6]. By using a blowing at the intake of the shroud and an airfoil formed ring-flap at the diffuser outlet, flow separation was prevented and the power production increased in the study by Igra [7]. $20 \%$ increase in power output was obtained when a blowing was used at the intake, and a $65 \%$ increase in power was obtained when an airfoil-shaped ring-flap was used. Igra experimentally studied a shrouded aero generator in a wind tunnel [8]. The model generated about $100 \%$ more power than that produced by a perfect wind turbine in similar conditions. Foreman and Oman studied the diffuser in technical and economical terms to investigate the possibility of increasing the efficiency of a wind turbine (DAWT) [9]. They attained a considerable power increase from DAWT, which is two times greater than the power generated by the bare wind turbine. The increased power was created as a result of the low pressure at the exit of the diffuser pumping a great deal of air via the DAWT as compared to a usual wind turbine.

The parameters affecting the performance of the diffuser system within the wind tunnel were assessed by Gilbert [10]. The first DAWT generation in their work produced power that doubled the usual WECS (Wind Energy Conversion System) when subjected to operating conditions similar to that presented by Igra [8]. The performance and design of an axial flow turbine were evaluated by Igra and were found to be appropriate for the suggested shrouds [11]. The power generation augmentation factor was in the range of $2-4$. Theoretical, experimental, and numerical examinations were performed by Phillips and Richards on a Vortec 7 wind turbine, and a comparison was made between the former and experimental works [12]. It was found that there was agreement between field measurements and Computational Fluid Dynamics (CFD). Numerous field outcomes were also consistent with the former investigation results. A comparison was made by Hansen et al. between the CFD calculations of a bare turbine and the theoretical equation expressing the power coefficient as a function of the thrust coefficient [13]. It was observed that the Betz limit could be surpassed with a ratio relative to the increase in mass flow rate when implementing duct. Abe and Ohya studied the flow fields around a flanged diffuser utilizing CFD for developing small-type 1.5 kilowatt wind turbines [14]. A comparison between the findings and the equivalent existing statistics indicated that the design of Abe and Ohya was capable of offering rational predictions for complex turbulent flow. Hence, it was shown that the performance of a flanged diffuser intensely relied on the loading coefficients and the opening angles. In the research by Ohya and Karasudani, it was found that the hollow-structure diffusers acted as shroud-type wind turbines to collect and accelerate the wind [15]. Moreover, they indicated that the application of a flange with an appropriate height linked to the outer boundary of the diffuser exit attained a significant increase in wind speeds. The reason for this increase in speed can be attributed to the low-pressure region created within the exit area of the diffuser due to the vortex creation, drawing the wind toward the diffusers [15]. Numerical and experimental assessments were performed by Abe et al. for the flow field of small wind turbines possessing flanged diffusers [16]. They demonstrated that the wind turbine with a shrouded diffuser had a power coefficient almost four times the bare wind turbine. Moreover, this wind turbine achieved increased power output mostly due to the acceleration of the pending wind by a flanged diffuser. In a study of Matsushima et al., the impacts of a frustum-formed diffuser on the output power of small wind turbines were investigated numerically and experimentally [17]. They indicated that the considered diffuser parameters could increase the highest wind speeds at the entrance of the diffuser by about 1.7 times. Moreover, the highest energy production ratios of around 2.4 times were acquired by gathering wind energy into the turbine. A scoop was used by Wang and Bai for improving the energy capture by a wind turbine with a low wind speed. They utilized physical tests performed in a commercial CFD code and boundary layer wind tunnel to obtain an optimum scheme for the scoop. The ultimate scoop design increased the airflow speeds by 1.5 times following an increase in power outputs of 2.2 times with equivalent swept areas [18]. Raj and Nair developed and analyzed a three-dimensional CFD model for shrouded wind turbines with flanges using GAMBIT within FLUENT commercial software [19]. They demonstrated an acceptable similarity between former experimental works and their numerical investigations. A very compacted and brimmed diffuser was developed by Ohya and Karasudani and it produced an output power two to three times greater than the conventional wind turbines [20]. PIV and numerical simulations were investigated by Kardous et al. to reach a deeper understanding of the effects of the flange heights on the rate of increase in the velocity of wind at the inlet of a flanged diffuser. They found the role of the flange in increasing the wind speed in the diffuser at the inlet segment [21]. Increase in wind velocities by the diffuser with no flange was around $58 \%$; however, this increase was within the range of $64-81 \%$ for the flanged one, and it seemed that the flange height had no considerable role in increasing wind velocities at a ratio of flange height to throat diameter equal to 0.1. El-Zahabi and Kabeel numerically studied the effects of flange angle on the output power of shrouded wind turbines. They realized that an angle of 15 degrees yielded the best 
efficiency [22]. In a different research, effects of number and attack angles of blades on rotational speed were experimentally studied in a duct [23]. The results demonstrated that wind velocity increased up to 2.46 times numerically and 2.32 times experimentally in the optimized case. Angle of attack of 75 degrees and threeblade turbine yielded the most efficient case. In another work, a small wind turbine was studied experimentally at low speeds in the range of $2.5-4.5 \mathrm{~m} / \mathrm{s}$ [24]. Different blade numbers including 2,3 , and 4 blades were tested. The results indicated that the wind turbine with a diffuser and 3 blades had the best performance. Another idea was investigated upon comparing a wind turbine with a diffuser with a wind turbine with a diffuser and an inlet shroud [25]. The outcomes demonstrated that the highest increase of power efficiency was achieved in the case of the wind turbine with diffuser and inlet shroud and it was about $41 \%$.

Siavash et al. proposed a new mathematical model of shrouded wind turbines. They reported that an optimized shrouded wind turbine might experience a power coefficient of 0.93 in the best situation [26]. Parsa and Maftouni conducted a comparative study of three different models for a large-scale wind turbine, namely bare, simple shrouded, and flanged wind turbines. Their results demonstrated that the implementation of a simple shroud led to a $106 \%$ increase in output power and the use of a flanged shroud led to a $137 \%$ increase [27]. Khamlaj and Rumpfkeil performed numerical optimization of the wind turbine by making some changes to diffuser curve and the flange height to increase the output power. They used the multi-objective genetic algorithm method for optimization [28]. Lipian et al. designed an innovative wind system including two small rotors inside a shroud [29,30]. The outcomes demonstrated that while augmenting the wind turbine performance, the application of shroud increased the load on the rotor. An application of the second rotor was proposed to reduce this shortage. It provided a modest increase in efficiency (about 12\% for the bared turbine and $5 \%$ for shrouded turbine), but resulted in an even distribution of load on the rotors.

In the current research, a numerical study is performed to illustrate the effects of shrouded flange surface types on the velocity of the wind entering the shroud or approaching the turbine. Different surface types are studied and output power is calculated in each case. Here, the main objective is to determine the optimum surface type of the flange for the first time in the literature.

\section{Materials and methods}

In the present study, a CFD analysis was conducted to determine the best surface type for the flanges in shrouded wind turbines. Here, the flow was considered unsteady, incompressible, turbulent, and 2D. A $k-\varepsilon$ model was considered to simulate turbulence.

Figure 1 shows a schematic of the flanged shroud. The dimensions of the solution domain, shown in Figure 2, are chosen in line with the research by Abe and Ohya [14]. Table 1 presents the dimensions of the shroud. This design aims to optimize the proposed dimensional relations in Ohya and Karasudani [15].

Figure 3 shows the boundaries of the problem. To apply proper boundary conditions, $U=U_{\infty}$ and $V=0$ are assumed at the inlet of the domain (boundary 1). At the outlet of the domain (boundary 5), flow $w_{i n}$ is assumed equal to flow out and the flow is considered incompressible. For the top and bottom of the domain (boundary 4) and the walls of the shroud body (boundary 3 ), the no-slip boundary condition is applied and velocities are considered to be $U=0$ and $V=0$. For boundary 2, a symmetric axis condition is assumed.

A triangle mesh type is used to make the computational grid. To ensure a reliable grid, the meshindependency study is performed. The maximum air velocity is calculated for five different grids. The results are reported in Figure 4 . It is obvious that there is no difference in the results when increasing the total numbers of the mesh elements beyond 19534 .

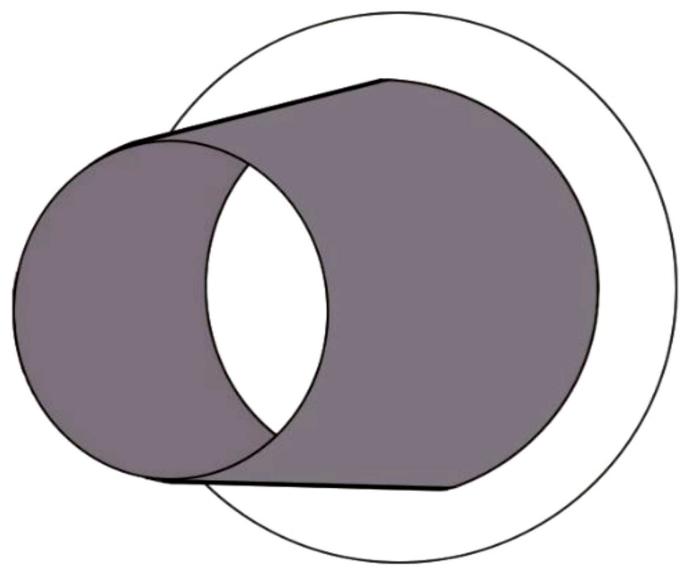

Figure 1. Schematic of a flanged shroud.

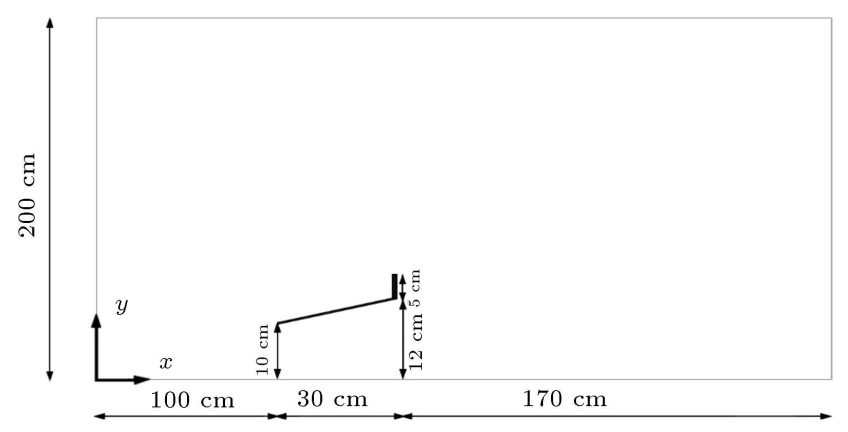

Figure 2. The solution domain and schematic of the problem. 
Table 1. Dimensions of the simulated shroud.

\begin{tabular}{ll}
\hline Inlet diameter, $D_{1}$ & $20 \mathrm{~cm}$ \\
Outlet diameter, $D_{2}$ & $24 \mathrm{~cm}$ \\
Length of shroud, $L$ & $30 \mathrm{~cm}$ \\
Thickness of shroud & $2 \mathrm{~mm}$ \\
Thickness of flange & $4 \mathrm{~mm}$ \\
Height of flange, $h$ & $5 \mathrm{~cm}$ \\
\hline
\end{tabular}

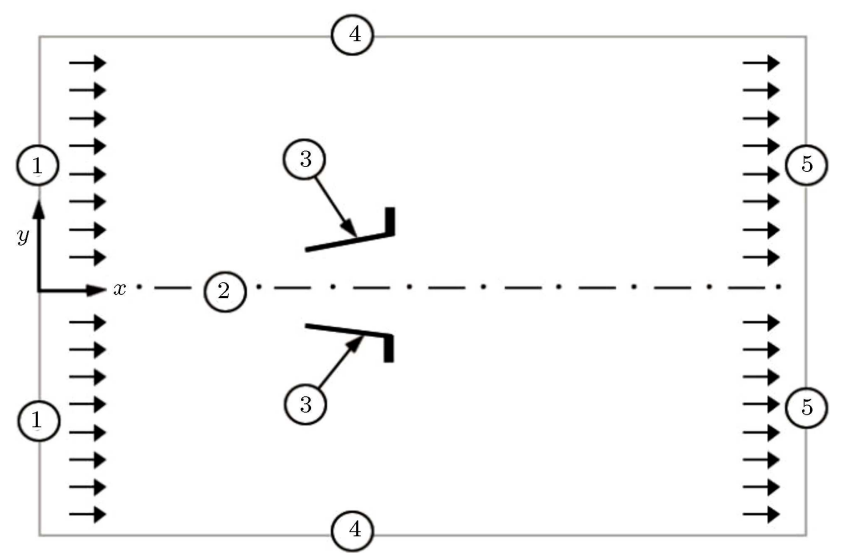

Figure 3. Schematic diagram of the boundaries in the system.

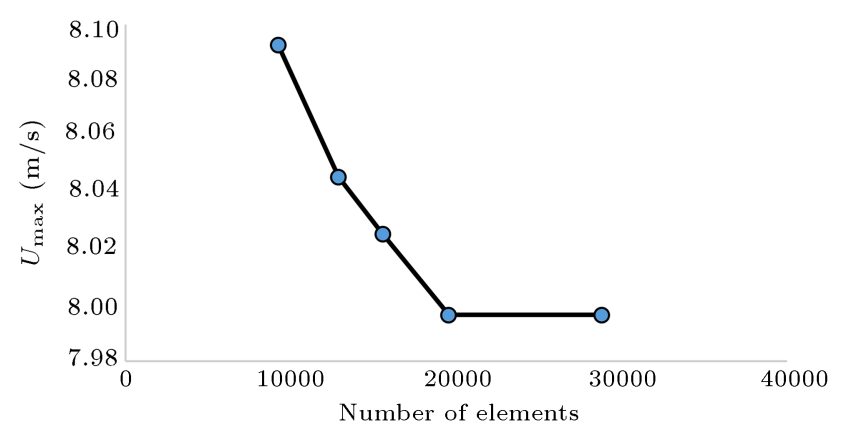

Figure 4. Mesh independency study results.

Therefore, the fourth grid is selected to optimize the calculation cost while obtaining accurate results.

For the first time, some different flange surface types are modeled, simulated, and analyzed to achieve the optimum case with the highest maximum velocity. Two views of the meshed systems are reported in Figures 5 and 6 . The whole system in the case of a simple flange surface is shown in Figure 4. The detailed mesh near the flange surface is obvious in Figure 5 for the surface of circular furrowed type.

Figure 7 shows the side views of these surfaces. One model is a simple flange and the other is a furrowed flange with circular furrows of $2 \mathrm{~mm}$ diameter.

\section{Validation}

The base model is validated with the experimental

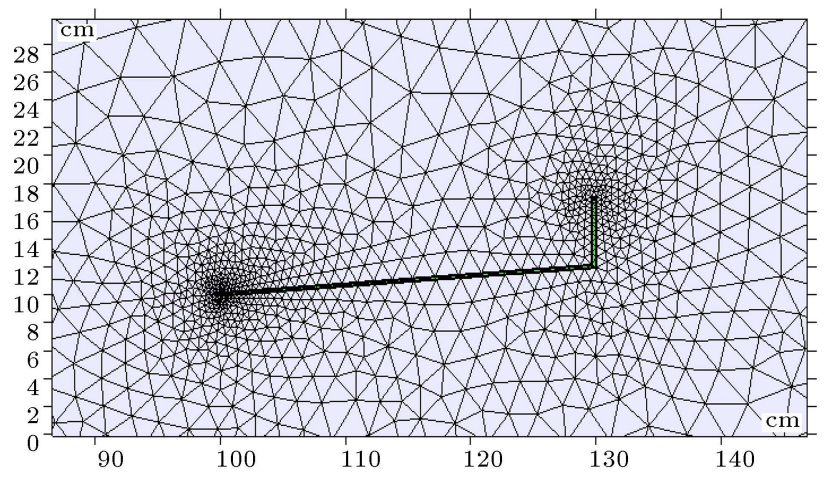

Figure 5. A view of the meshed system (flange with the simple surface).

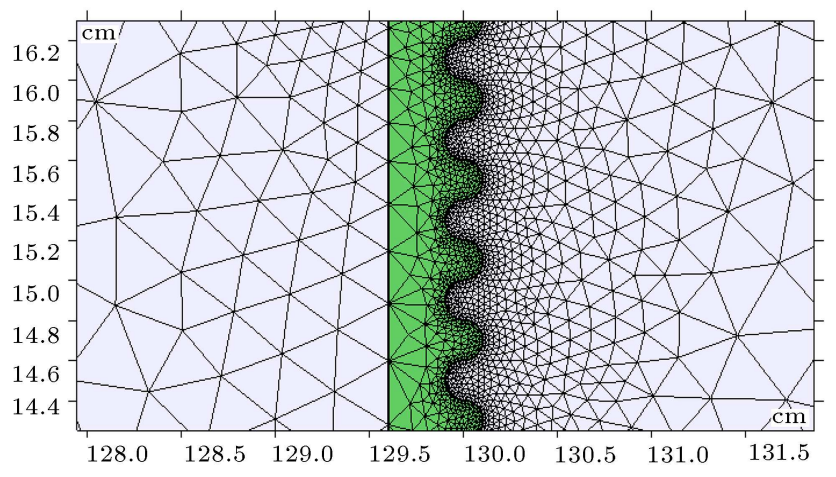

Figure 6. A view of the meshed flange surface with circular furrows.

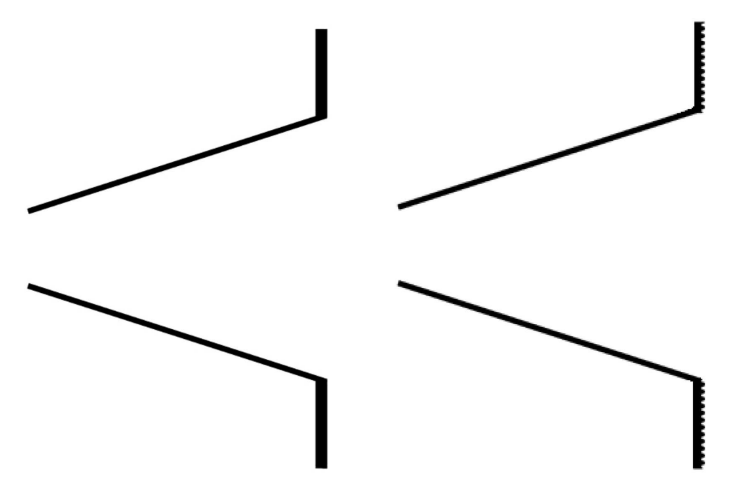

Figure 7. Different flange surface types: (a) Simple flange surface and (b) furrowed flange surface.

results published by Gilbert [10]. The experiment was performed in a subsonic open wind tunnel. The wind tunnel was $3.6 \mathrm{~m}$ wide, $2 \mathrm{~m}$ high, and $15 \mathrm{~m} \mathrm{long}$, and the maximum wind speed in the tunnel was $30 \mathrm{~m} / \mathrm{s}$. An I-type hot wire velocity meter was used to measure distributions of wind speed. To visualize the flow, the smoke-wire method was employed.

Here, the shroud is modeled under the same conditions as the experimental study. Figure 8 compares the velocity ratio of local velocity to free stream velocity, $U=5 \mathrm{~m} / \mathrm{s}$ along the shroud, in both cases of numerical and experimental studies. The difference 


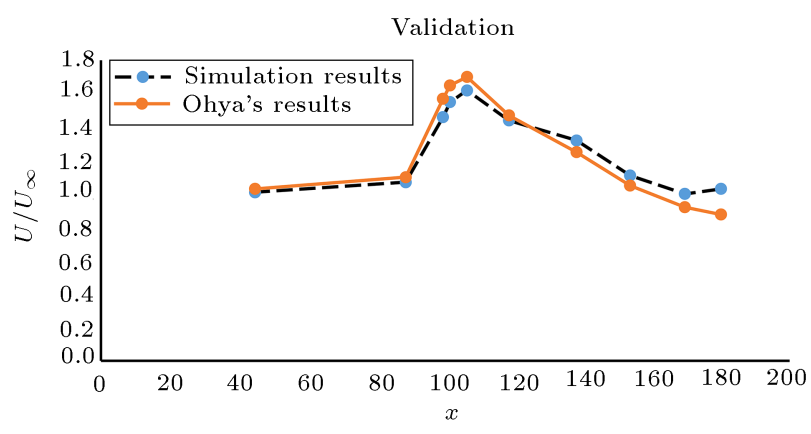

Figure 8. Comparison between Computational Fluid Dynamics (CFD) results and experimental data of Ohya and Karasudani [15].

between the two graphs, reported in Figure 8, ranges from $0.21 \%$ to $4.3 \%$. Thus, good agreement is observable between the simulation results of the present work and the experimental results achieved by Ohya and Karasudani [15].

\section{Results and discussion}

For the simple surface and the furrowed surface with circular furrows, the velocity contours are presented in Figures 9 and 10, respectively.

It should be mentioned that because of the small size of the shroud in comparison with the solution

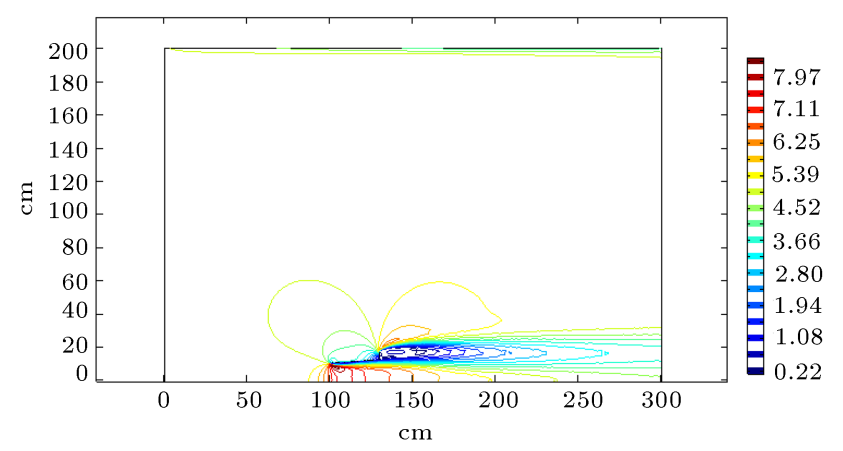

Figure 9. The velocity contour for the case of a flange with a simple surface.

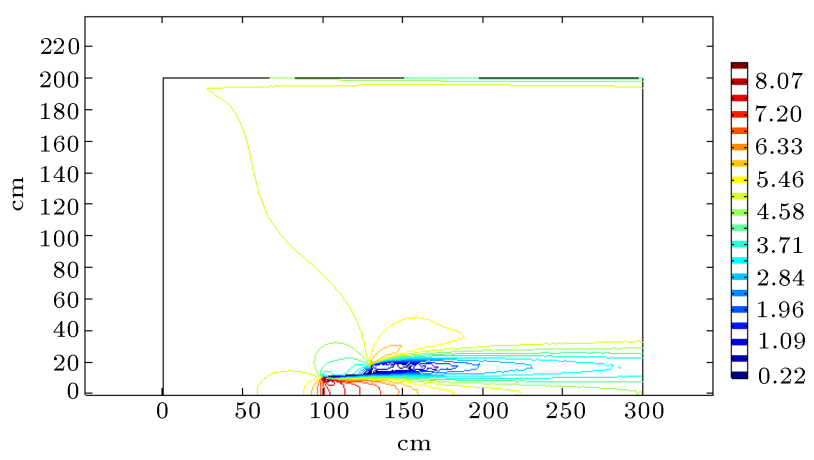

Figure 10. The velocity contour for the case of a flange with a furrowed surface with circular furrows. domain, it is not possible to observe the furrows on the flange in these contours.

The graphs of velocity are shown in Figures 11 and 12 for the simple surface and the surface with circular furrows.

It is observable that implementing a furrowed flange surface type results in the velocity increase in the shroud inlet region. This surface type produces a larger wake and, consequently, a stronger negative-pressure region. Hence, the wind velocity increases more when approaching the turbine.

The velocity graphs also indicate that the maximum wind velocity occurs at about $5 \mathrm{~cm}$ after the entrance of the shroud. Thus, it is recommended that the wind turbine be installed at that location.

It should be mentioned that this study made an attempt at some other geometries for the furrow shapes, including square and wedge shapes, and found the results very similar.

Figures 13 and 14 show the pressure contours of the system for the simple surface and the surface with circular furrows, respectively. Accordingly, the lowpressure region is stronger near the shroud end in the case of the flange surface with circular furrows. Also, the pressure graphs are shown in Figures 15 and 16 for both cases.

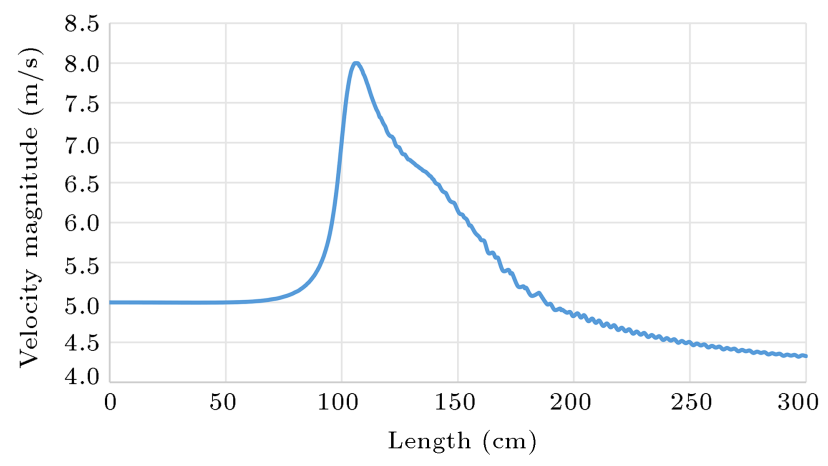

Figure 11. The graph of velocity for the simple flange surface.

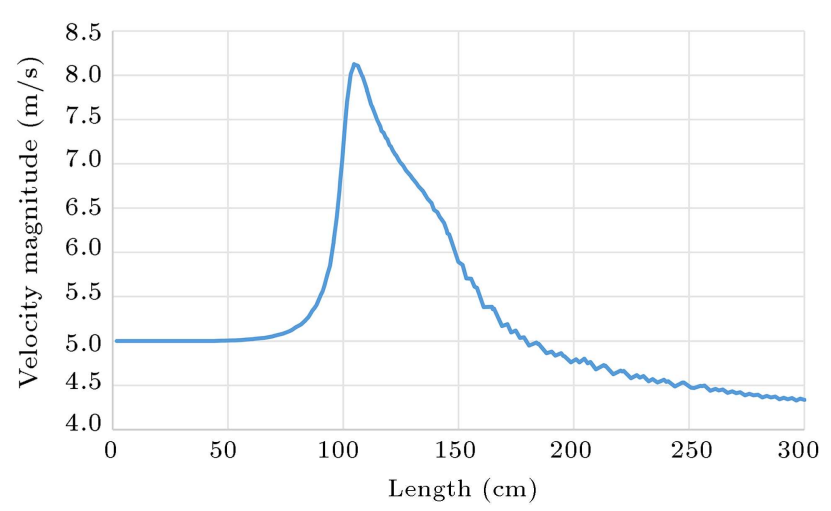

Figure 12. The line graph of velocity for the flange surface with circular furrows. 


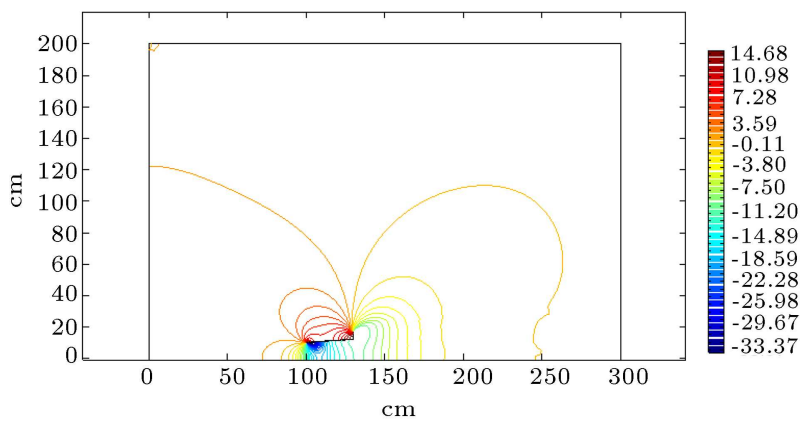

Figure 13. The pressure contours of the system for the simple flange surface.

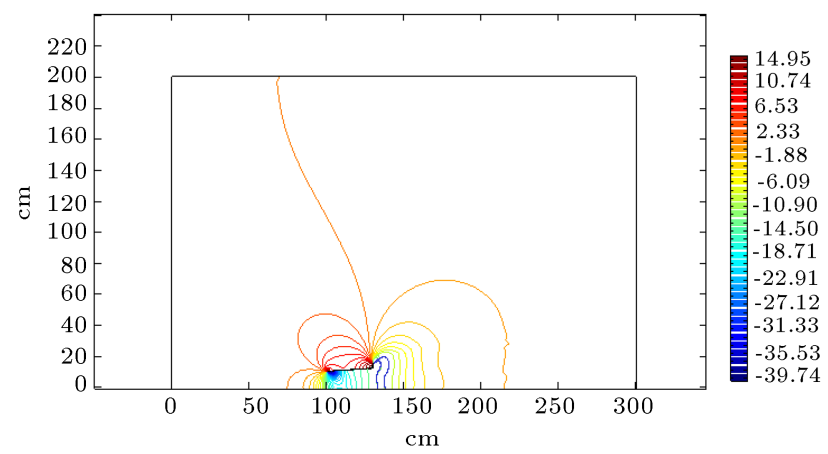

Figure 14. The pressure contours of the system for the flange surface with circular furrows.

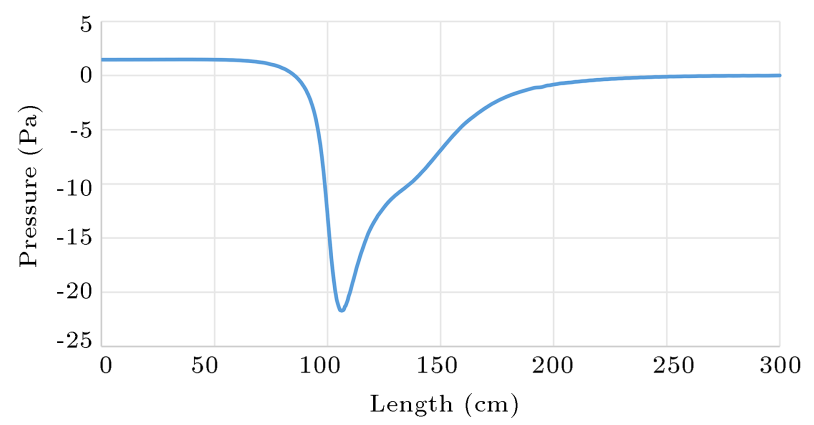

Figure 15. The graph of pressure for the simple flange surface.

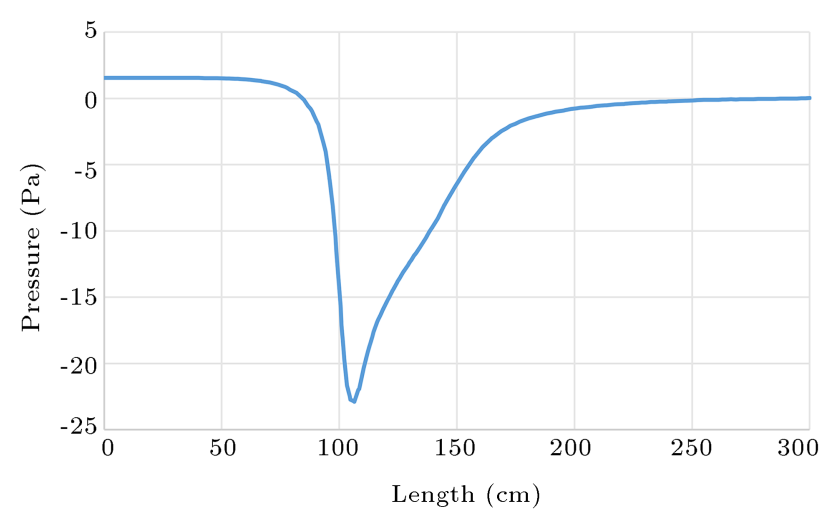

Figure 16. The graph of pressure for the flange surface with circular furrows.
The pressure graph for the simple flange surface type shows a pressure about $-11 \mathrm{~Pa}$ at the outlet of the shroud, while this is about $-13 \mathrm{~Pa}$ for the flange surface with circular furrows. As mentioned before, some other furrow types were simulated and tested and similar results were obtained. It was found that making furrows in any shape would lead to the presence of more vortexes and, consequently, a greater pressure decline. Therefore, the velocity increases to compensate for the pressure drop by sucking a greater mass of air through the shroud. The power harvested by a horizontal wind turbine is proportional to the cube of the wind velocity. Thus, the generated power in each case can be calculated. The results are very similar and in all cases, an increase of about $5-7 \%$ is observed in the harvested power for all of the furrowed surface types in comparison with the simple-surface flange.

\section{Conclusion}

The characteristics of flow in the shroud of a wind turbine and around it for different flange surface types were studied numerically. Results demonstrated that there was a decline in pressure in all cases, representing a region with negative pressure. This negative pressure was more significant in the case of the furrowed flange surfaces. Hence, the air velocity increased more when entering the shroud in these cases. The expected power increase for the furrowed flange surface types was about $5-7 \%$ when compared with the shroud with a simple-surface flange. The results also point to no significant difference in power increase due to various shapes of the furrows including circular, square, and wedge types. In all of the cases, the maximum wind velocity occurred at about $5 \mathrm{~cm}$ from the shroud entrance. A strong correlation was observed when the simulated results were compared with the experimental ones obtained from the literature. For this reason, it was proposed that the wind turbine was placed at that location. Regarding the simple geometrical modifications required to achieve the furrowed surface type of flanges, both for new shrouded wind turbines and old ones, the results of this study could be used in industrial applications.

\section{Nomenclature}

$U \quad$ Horizontal velocity $(\mathrm{m} / \mathrm{s})$

$V \quad$ Vertical velocity $(\mathrm{m} / \mathrm{s})$

$U_{\infty} \quad$ Infinity velocity $(\mathrm{m} / \mathrm{s})$

\section{References}

1. Khojasteh, H. and Norollahi, Y. "Optimization of power and levelized cost for shrouded turbine", Invention, 59, pp. 1-13 (2020). 
2. Avallone, F., Ragni, D., and Casalino, D. "On the effect of the tip-clearance ratio on the aeroacoustics of a diffuser-augmented wind turbine", Renewable Energy, 152, pp. 1317-1327 (2020).

3. Siavash, N.K. and Najafi, G. "An innovative variable shroud for micro wind turbines", Renewable Energy, 145, pp. 1061-1072 (2020).

4. Siavash, N.K. and Ghobadian, B. "Prediction of power generation and rotor angular speed of a small wind turbine equipped to a controllable duct using artificial neural network and multiple linear regression", Environmental Research, Available online 6 November 2020, 196, 110434 (2021).

5. Said, M., EL-Shimy, M., and Abdelraheem, M.A. "Improved framework for techno-economical optimization of wind energy production", Sustainable Energy Technologies Assessment, 23, pp. 57-72 (2017).

6. Lilley, G.M. and Rainbird, W.J. "A preliminary report on the design and performance of ducted windmills", Report 102, College of Aeronautics, Cranfield, England (1957).

7. Igra, O. "Compact shrouds for wind turbines", Energy Conversion and Management, 77, pp. 90022-5 (1977).

8. Igra, O. "The shrouded aerogenerator", Energy, 77, pp. 90006-18 (1977).

9. Foreman, B.G. and Oman, R.A. "Diffuser augmentation of wind turbines", Solar Energy, 78, p. 90122-6 (1978).

10. Gilbert, B.L. "Fluid dynamics of diffuser-augmented wind turbines", Energy, 6, pp. 368-374 (2012).

11. Igra, O. "Research and development for shrouded wind turbines", Energy Conversion and Management, 21, pp. 13-48 (1981).

12. Phillips, D.G. and Richards, P.J. "Aerodynamic analysis and monitoring of the Vortec diffuser augmented wind turbine", IPENZ Conference, Auckland, New Zealand, pp. 12-16 (1998).

13. Hansen, M., Sorensen, N.N., and Flay, R. "Effect of placing a diffuser around a wind turbine", Fluid Mechanics, 3, pp. 207-213 (2000).

14. Abe, K. and Ohya, Y. "An investigation of flow fields around flanged diffusers using CFD", J. Wind Engineering and Industrial Aerodynamics, 92, pp. 315-330 (2004).

15. Ohya, Y. and Karasudani, T. "Development of a shrouded wind turbine with a flanged diffuser", $J$. Wind Engineering and Industrial Aerodynamics, 96, pp. 524-539 (2008).

16. Abe, K., Nishida, M., Sakurai, M.A., et al. "Experimental and numerical investigations of flow fields behind a small-type wind turbine with flanged diffuser", J. Wind Engineering and Industrial Aerodynamics, 93, pp. 951-970 (2005).

17. Matsushima, T., Takagi S.H., and Muroyama, S. "Characteristics of a highly efficient propeller type small wind turbine with a diffuser", Renewable Energy, 31, pp. 1343-54 (2006).

18. Wang, F. and Bai, L. "The methodology for aerodynamic study on a small domestic wind turbine with scoop", J. Wind Engineering and Industrial Aerodynamics, 96, pp. 1-24 (2008).

19. Raj, U.I. and Nair, A.S. "Development of 3d CFD model of a shrouded wind turbine", In 10th National Conference on Technological Trends, Kerala, India (2009).

20. Ohya, Y. and Karasudani, T. "A shrouded wind turbine generating high output power with wind-lens technology", Energies, 3, pp. 634-649 (2010).

21. Kardous, M. and Chaker, R. "On the dependence of an empty flanged diffuser performance on flange height: Numerical simulations and PIV visualizations", Renewable Energy, 56, pp. 123-128 (2013).

22. El-Zahaby, A.M. and Kabeel, A.E. "CFD analysis of flow fields for shrouded wind turbine's diffuser model with different flange angles", Alexandria Engineering Journal, 56, pp. 171-179 (2017).

23. Ahmadi Asl, H., Kamali Monfared, R., and Rad, M. "Experimental investigation of blade number and design effects for a ducted wind turbine", Renewable Energy, 105, pp. 334-343 (2017).

24. Pambudi, N.A., Pristiandaru, D.L., Basori, B., et al. "Experimental investigation of wind turbine using nozzle-lens at low wind speed condition", Energy Procedia, 105, pp. 1063-1069 (2017).

25. Rianto, R., Pambudi, N.A., Febryanto, R., et al. "The performance of shrouded wind turbine at low wind speed condition", Energy Procedia, 158, pp. 260-265 (2019).

26. Siavash, N.K., Najafi, G., Tavakkoli Hashjin, T., et al. "Mathematical modelling of a horizontal axis shrouded wind turbine", Renewable Energy, 146, pp. 856-866 (2020).

27. Parsa, H. and Maftouni, N. "Optimization of a real scale shrouded wind turbine using 3D CFD analysis", International Journal of Renewable Energy Research, 10, pp. 922-932 (2020).

28. Khamlaj, T.A. and Rumpfkeil, M.P. "Analysis and optimization of ducted wind turbines", Energy, 162, pp. $1234-52$ (2018).

29. Lipian, M., Dobrev, I., Karczewski, M., et al. "Small wind turbine augmentation: Experimental investigations of shrouded- and twin-rotor wind turbine systems", Energy, 186, p. 115855 (2019).

30. Lipian, M., Dobrev, I., Massouh, F., et al. "Small wind turbine augmentation: Numerical investigations of shrouded- and twin-rotor wind turbines", Energy, 201, p. 117588 (2020).

\section{Biographies}

Negin Maftouni was born in Tehran, Iran, 1978. She received the BSc degree from K.N. Toosi University, 
Tehran, Iran, MSc degree from Sahand University of Technology, Tabriz, Iran, and the PhD degree in Nanomechanical Engineering from University of Tehran, Tehran, Iran. She has been a faculty member at the Department of Mechanical Engineering at Alzahra University, Tehran, Iran since 2014. Her research interests include renewable energy resources, building energy optimization, and nanobio-mechanics.
Mobina Taghaddosi was born in Tehran, Iran, 1997. She received the BSc degree from Alzahra University, Tehran, Iran. She is studying MSc at Iran University of Science and Technology, Tehran, Iran. She ranked first in Bachelor Program among students at the Department of Mechanical Engineering at Alzahra University, Tehran, Iran. Her research interests include renewable energy, robotics, and building energy optimization. 